\title{
Phenology of myxomycetes in Turrialba, Costa Rica
}

\section{Carlos Rojas ${ }^{1,2,}$, Pedro A. Rojas², Steven L. Stephenson ${ }^{3}$}

\footnotetext{
1 Finca Experimental Interdisciplinaria de Modelos Agroecológicos, University of Costa Rica, La Suiza de Turrialba, 30502-Costa Rica

2 Engineering Research Institute, University of Costa Rica, San Pedro de Montes de Oca, 11501-Costa Rica

${ }^{3}$ Department of Biological Sciences, University of Arkansas, Fayetteville AR 72701, USA
}

* Corresponding author:

carlos.rojasalvarado@ucr.ac.cr

Keywords: biodiversity, climate, El Niño-Southern Oscillation, monitoring, Neotropics,

sampling effort, slime molds

Article info:

Received: 24 February 2021

Accepted: 05 April 2021

Published online: 11 May 2021

Corresponding Editor: Riikka Linnakoski

\section{Abstract}

Long-term monitoring and phenological patterns of microbial communities are rare in the scientific literature. Myxomycetes have life cycle characteristics that allow both to be documented. The present study summarizes the integrated floristic and bioclimatic components of a 30-month assessment of myxomycete sporocarps in a premontane tropical forest in Turrialba, Costa Rica. Based on monthly visits and a standard sampling effort of 120 minutes per visit, myxomycetes were recorded on leaves, twigs, and logs on the ground by two to three people in 20-minute periods associated with six different collecting sites within a 34-hectare successional forest patch. Biological data were analyzed using three recorded climatic variables obtained in situ during the complete period of study. Also, the Oceanic Niño Index (ONI), provided by NOAA, an estimate of El Niño-Southern Oscillation (ENSO), was evaluated in the analyses. Overall, 54 species and 2245 records of myxomycetes were recorded, with an average of 14.5 species (range between 6-24) and 78.4 records (range between 20-110) detected each month. In general, neither the number of records nor the 
number of species were associated with individual climate variables, but multiple regression analyses showed that a combination of the accumulated precipitation of the four days before sampling and the average relative humidity can explain most of the fruiting dynamics $\left(R^{2}=0.56\right)$. When the ONI index was included in the analyses, the explained variability increased $\left(R^{2}=0.64\right)$, and when a categorization of months based on the same index was used, analyses showed that both the number of records and species evenness were affected by ENSO. At the species level, Hemitrichia calyculata was the only species observed during every month, closely followed by Arcyria cinerea, A. denudata, and Physarum compressum, recorded on most visits. Sporadic fruiting in some species such as Tubifera microsperma, P. tenerum, P. bogoriense, P. melleum, and Metatrichia vesparia could have been associated with local climate oscillations influenced by ENSO patterns. Phenological patterns were observed at the species level, indicating that in the Neotropics, under favorable conditions, myxomycete sporocarps are practically always present, but species assemblages vary temporally. These variations are primarily driven by local climate, but regional climate dynamics also affect fruiting patterns. Presumably, the remaining ecological effect on fruiting patterns in the Neotropics can be attributed to certain finer factors such as ecosystem structure, substrate quality/availability, and biotic interactions. As such, phenomena such as climate change can have an important effect on the production of sporocarps by tropical myxomycetes, with subsequent effects of their ecological dynamics.

\section{Introduction}

Myxomycetes are amoeboid organisms known to occur in most ecosystems on the planet (Schnittler et al. 2017). Despite the taxonomic focus of most historical studies, ecological information on this group of microorganisms has increased during the last decades (Stephenson et al. 2004; Dagamac et al. 2017, Bortnikov et al. 2020). Several topics such as habitat specificity, niche partitioning, and colonization dynamics have been studied during this time (Rojas et al. 2008; Rollins \& Stephenson 2013; Stephenson \& Rojas 2020). Currently, data obtained from the combination of molecular techniques and ecological approaches (Shchepin et al. 2019) provide integrated evidence for patterns that have been partially documented using only traditional techniques.

Despite the latter, there are still a number of ecological aspects of myxomycetes, with limited information, that can be evaluated using traditionally collected data. Phenology, for instance, defined as "the study of the timing of recurrence of biological events, the causes of their timing with regard to biotic and abiotic forces and the interrelation among phases of the same or different species" (Lieth 1974) is one example. Myxomycetes, as is the case for any other organisms, react to environmental forces and undergo their life cycle, recurrently visiting their reproductive phase. As such, myxomycete sporocarps, a visible product of the latter, are natural indicators of phenological patterns and can be used for the study of auto- or synecological issues.

For phenological assessments, large datasets comprised of a high number of independent observations collected at a similar temporal frequency over an extended period are necessary (Abernethy et al. 2018). For this type of evaluation on myxomycetes, such requirement can be a problem since long-term datasets on myxomycetes are not common (Novozhilov et al. 2017). The few exceptions include the studies of Eliasson in South Sweden (Eliasson 1981) and Stephenson in the North American Appalachians (Stephenson 1988). More recently, Schnittler et al. (2015) carried out a four-year study in the Caucasus, with discontinuous sampling. However, similar studies in tropical environments do not yet-to the best of our knowledge-exist, and phenological evaluations in such ecological systems rely on data collected in discrete studies carried out over shorter periods. This is relevant since the environmental pressures exerted on myxomycetes differ between boreal, temperate, and tropical systems (Rojas \& Stephenson 2020), and patterns of sporocarp production for phenological evaluations should be based on standard methodologies.

This background provided the basis of the present investigation, which was designed to study the diversity and abundance of species of myxomycet- 
es, based on sporocarps, in the Neotropics. Ongoing ecosystem studies in an experimental station in the city of Turrialba, Costa Rica (Quesada Chacón et al. 2020), allowed for a neutral evaluation of data over 30 months. As such, the present study not only provided evidence on patterns of myxomycete sporocarp occurrence but also on the interrelation of those patterns with contextual elements of the system such as forest structure and local climate, as suggested by Lieth (1974). In an excellent analysis by Tonkin et al. (2017), both seasonality and the predictability associated with biological observations were considered key elements for the determination of the effect of environmental variability on organisms. For myxomycetes, those analyses have yet to be carried out but will certainly use data from studies such as the present one.

\section{Materials and methods}

This study was conducted in the Finca Experimental Interdisciplinaria de Modelos Agroecológicos (FEIMA), a research station administrated by the University of Costa Rica and located near the city of Turrialba, Costa Rica. The land distribution at the station is based on three main zones, one of which is a 28-hectare successional forest patch (see Figure 1A), originally reforested about 35 years ago (in the late 1980s). Currently, the dominant elements across the forest patch are large Erythrina poeppigiana (Walp.) O.F. Cook and Castilla elastica Sessé ex Cerv.trees, but there are forest units containing Eucalyptus deglupta Blume (abbreviated as Fla in Figure 1A), Abarema idiopoda (S.F.Blake) Barneby \& J.W.Grimes (F2), and Enterolobium cyclocarpum (Jacq.) Griseb. (F3). The last two are members of the Fabaceae that have allowed the forest to recover efficiently (Figure 1B).

In FEIMA, a series of six sampling areas, two in each of the forest units, were delimited. In each area, a section of approximately $1000 \mathrm{~m}^{2}$ was surveyed for sporocarps of myxomycetes on a monthly basis during the period between February 2018 and August 2020. The exact section sampled was different every month to minimize the effect of repetitive sampling during previous months and increase representa- tiveness. Every field survey was carried out by two or three people, who spent about 20 minutes in each sampling area, for a total standard survey time of 120 minutes each month. During that time, all myxomycete sporocarps observed on coarse woody debris, leaf litter, twigs, and living plants up to $1.5 \mathrm{~m}$ from the ground were recorded and identified. This material was collected and deposited in the Myxogastrid Repository (INII) at the University of Costa Rica.

Parallel to the field surveys, three climatic variables were recorded in FEIMA during the entire period of the study. These variables were temperature (in ${ }^{\circ} \mathrm{C}$ ), relative humidity (in \%), and precipitation (in $\mathrm{mm}$ ) and were used to characterize the local climate. Due to the influence of El Niño-Southern Oscillation (ENSO) on the general climate of Costa Rica, the ONI (Oceanic El Niño Index) was used as an approximation to its effect. This monthly index, usually ranging between 2.5 and -2.5 in magnitude, is widely used to determine anomalies in the sea surface temperature of the Pacific Ocean that range from "warm" periods (higher than 0.5 , referred to as El Niño), "cold" periods (lower than -0.5, La Niña) and "neutral" periods (between -0.4 and 0.4). Stronger El Niño or La Niña events have values reaching the respective range extremes and weaker events are closer to the neutral limits.

The data corresponding to the local climate were averaged monthly for temperature and humidity and accumulated for precipitation. Based on the exact day of the field surveys, these data were averaged or accumulated for the previous 30 , seven and four days. In this manner, for instance, there were two monthly estimates for temperature, one for the natural month associated with the sampling and one for the period of 30 days before the survey. For meaningful phenological analyses, one estimate of each variable was selected based on correlation magnitude and significance in relation to the myxomycete data. As such, this primary selection of estimates determined that the average monthly temperature (Mtemp), the average monthly relative humidity (Mhumi), and the accumulated precipitation of the four days before the field surveys (4dPrec) were the best estimates to use in further analyses.

In this way, to reduce the dimensionality of climate data, integrate the regional ENSO information, and look for potential underlying mecha- 


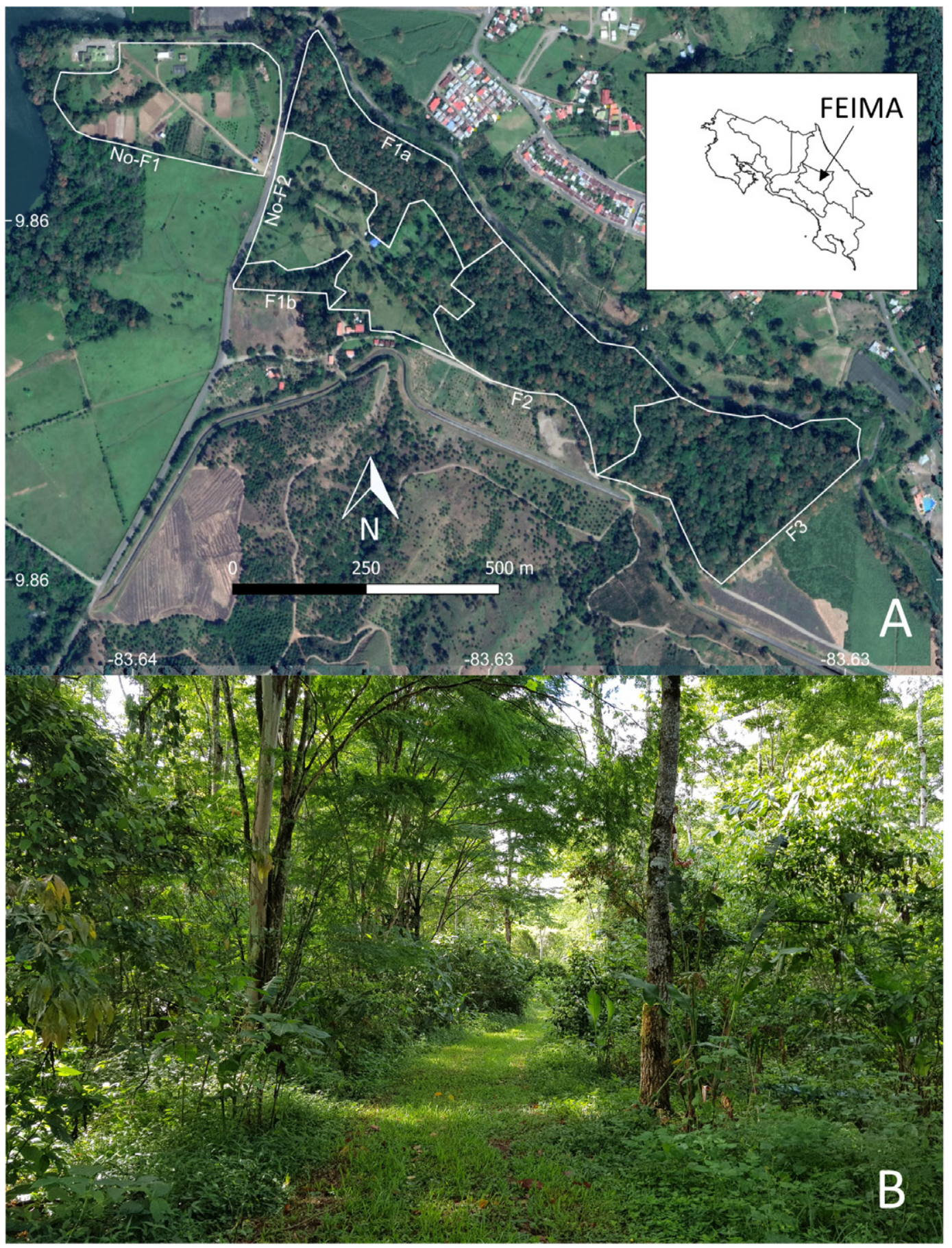

Figure 1. General view of the study area. A. Aerial photograph showing the perimeter of FEIMA and the zone division in the station (No-F1 = agricultural, No-F2 = cattle, F = forest - subdivided in three subzones F1, F2 and F3) and approximate location in Costa Rica (insert). B. Healthy vegetation surrounding a path into the tropical forest in a section dominated by Abarema idiopoda, a member of the Fabaceae. 
nisms driving the formation of sporocarps, a correlation-based Principal Component Analyses (PCA) was carried out using Mtemp, Mhumi, 4dPrec and ONI. A multiple regression analysis was carried out with the variables corresponding to the first two principal components and the individual effect of ONI was evaluated separately based on a stepwise approach. Both the Akaike Information Criterion (AIC) as well as the Bayesian Information Criterion (BIC) were used to determine the model that best explained the structure of the relationships. The ONI data were also used to categorize the respective month as warm, neutral or cold. Afterwards, differences in myxomycete data were evaluated across categories.

In all cases, the response variables to determine any phenological pattern in myxomycetes were species richness, species diversity-based on the Shannon's and Simpson's diversity indices-maximum number of species, and Shannon's evenness. The ratio of species to genera, known as the taxonomic diversity index, was also estimated. All indices were calculated in Past, v.4.01 and all statistical analyses such as t-tests and ANOVA, for two and three or more groups' comparisons, were carried out in JMP, v.10.0, with a cutoff value of 0.05 in the determination of the respective null hypotheses.

\section{Results}

A total of 2245 records of myxomycetes in 54 species were recorded during the period of study (Table 1). The forest unit with Enterolobium cyclocarpum (F3) present yielded the highest number of records and the highest diversity. There were significant differences in diversity between F2 and F3 using both Shannon's $(P=0.02)$ and Simpson's $(P=0.0002)$ diversity indices.

An average of $74.8 \pm 22.9$ records of myxomycetes in $14.5 \pm 3.5$ species were observed each month. The number of records ranged between 20-110, and the number of species ranged between 6-24 during the period of study. Similarly, the taxonomic diversity index ranged between 1.2-2.0, with an average of $1.6 \pm 0.2$ species per genus for the entire period. The patterns associated with each year of study were in- dependent, but in general data associated with the rainy second semester of each year showed lower variability and higher values than those recorded during the drier first semester (Figure 2). This was apparent for the number of records, with an average of 81 per month and a coefficient of variation of 29 during the second semester, and 69 records per month and a coefficient of variation of 32 during the first semester.

No simple correlations were found between either the number of records or the number of
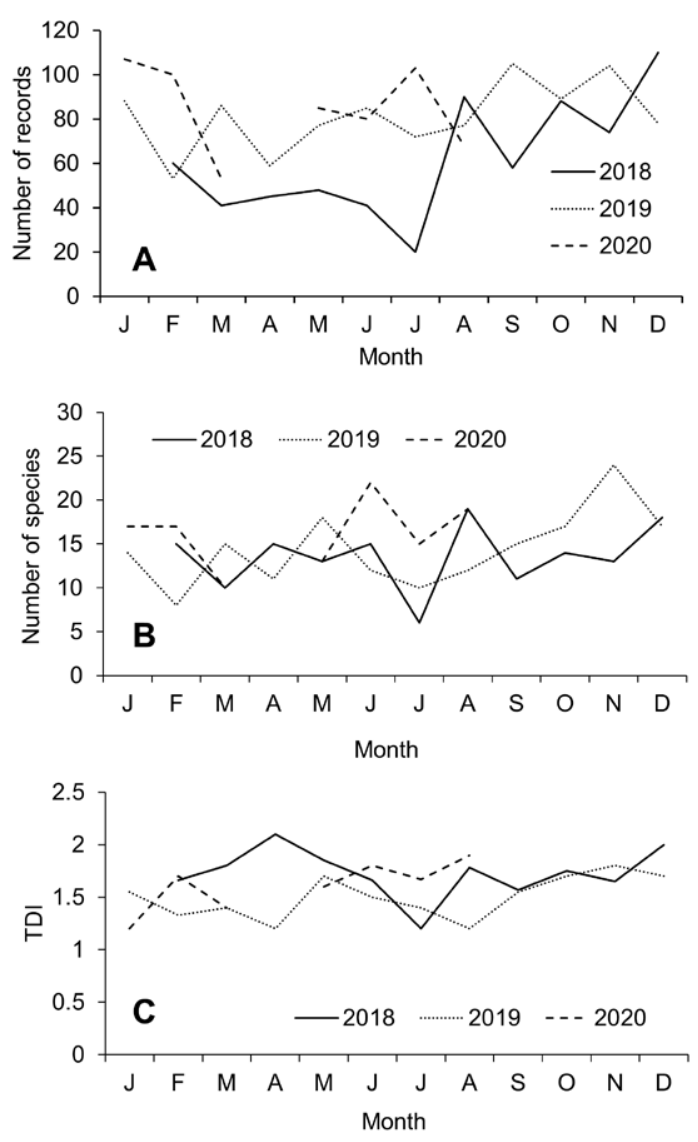

Figure 2. Temporal oscillations in the number of records (A), number of species (B) and taxonomic diversity index (C) observed in the present study. April 2020 shows the only gap in the data as a product of travel restrictions due to the COVID-19 pandemic. 

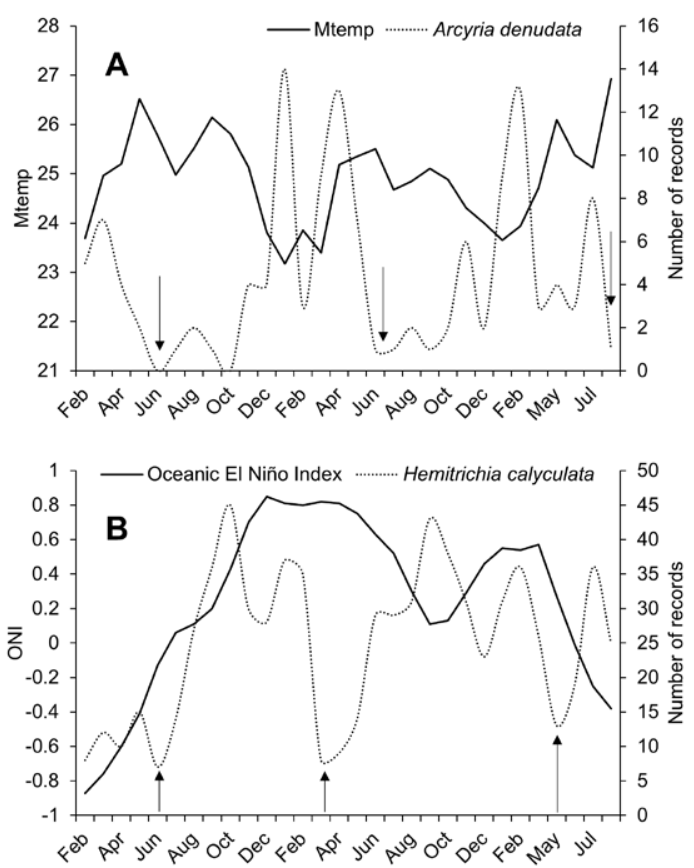

Figure 3. Number of records observed during the present study for Arcyria denudata (A) and Hemitrichia calyculata $(B)$ in association with Mtemp $(r=-0.53)$ and $\mathrm{ONI}(r=0.34)$, respectively. The lowest values shown with the arrows suggest the seasonality of sporocarp production.

species and any climatic variable. A similar situation was observed for the diversity indices, the evenness values, and the maximum number of species. No differences were noted among the values for average monthly temperature, average temperature of the previous seven days, and average temperature of the previous four days $(F(2,85)=0.17, P=0.83)$, and no differences were observed between the accumulated precipitation of the previous seven days and the accumulated precipitation of the previous four days $(t=0.87, P=0.38)$. Although low in magnitude, the highest correlation values with response variables were observed for the average monthly temperature (Mtemp) and the accumulated precipitation of the previous four days (4dPrec).
In the Principal Component Analysis, 4dPrec and Mhumi were the first two principal components and accounted for about $75 \%$ of the data structure. The multiple regression analysis for the number of records using the latter two climatic variables resulted in an $r^{2}=0.56$ with no autocorrelation and clear heterocedasticity. The resulting model was: NR $=-352.6+5.7$ (Mhumi)-0.37(4dPrec)-0.54((Mhumi -76.5)(4dPrec-8.7)) Ec.1 where NR = Number of records, Mhumi $=$ average monthly relative humidity and $4 \mathrm{dPrec}=$ accumulated precipitation of the previous four days. When the ONI was added to the model, the $r^{2}$ value of the resulting correlation increased to 0.64 with the resulting model: $\mathrm{NR}=-242.5+4.3(\mathrm{Mhu}-$ mi)-6.8((ONI-0.24)(Mhumi-76.5))-0.74((Mhumi-76.5) (4dPrec-8.7)) Ec.2 where NR = Number of records, $\mathrm{ONI}=$ Oceanic El Niño Index, MHumi $=$ average monthly relative humidity and $4 \mathrm{dPrec}=$ accumulated precipitation of the previous four days.

With the latter equation, both the AIC and the BIC decreased by approximately $2 \%$ in relation with the model shown in the first equation, making it more accurate to determine the response variable. When ONI values were used to categorize cold, neutral or warm periods, differences were observed in both the number of records and species evenness $(F(2,27)=3.42, P=0.04 ; F(2,27)=3.95, P=0.03$, respectively) associated with these categories. In both cases, differences were based on the comparisons between cold-warm periods $(P<0.05)$. The average number of records followed the progression 83-72-48 for warm, neutral and cold periods, and the average evenness was $0.75-0.57-0.54$ for the same categories, showing that warm periods were associated with higher numbers and more even patterns of sporocarp production in the field.

Only Hemitrichia calyculata (Speg.) M.L. Farr was recorded during every month of the study, but other species such as Arcyria cinerea (Bull.) Pers., Arcyria denudata (L.) Wettst., Ceratiomyxa fruticulosa (O.F. Müll.) T. Macbr., Physarum compressum Alb. \& Schwein. and Stemonitis fusca Roth were recorded in more than $85 \%$ of the field surveys. When these species were closely analyzed in relation with the climatic data, results showed that the number of records for each of them could be primarily linked to a climate variable. Also, in most cases, a degree of seasonality was suggested by the data. 

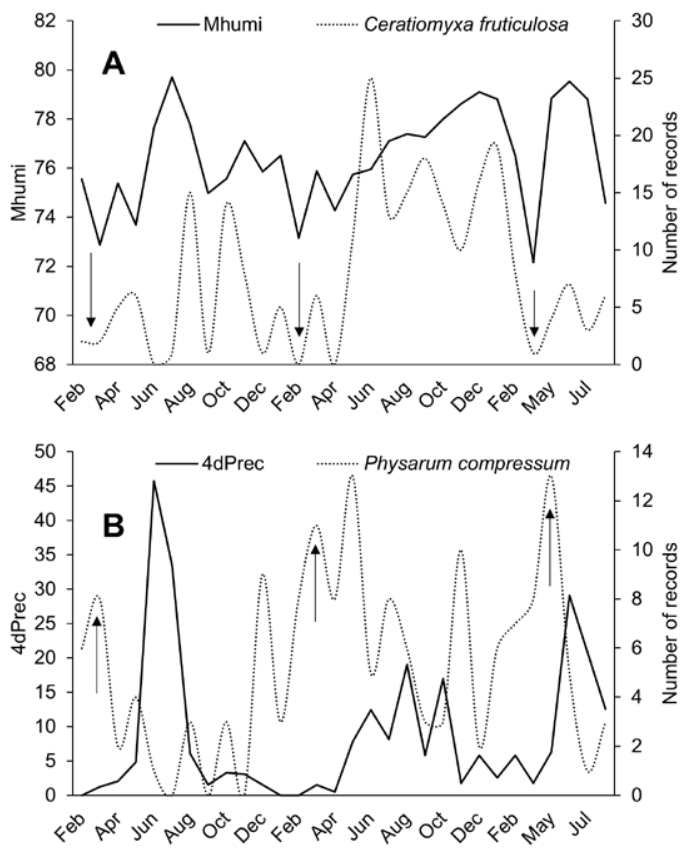

Figure 4. Number of records observed during the present study for Ceratiomyxa fruticulosa (A) and Physarum compressum (B) in association with Mhumi $(r=0.36)$ and 4 dPrec $(r=-0.37)$, respectively.

The highest and lowest values shown with the arrows suggest the seasonality of sporocarp production.

The highest correlation was observed between the number of records of $A$. denudata and Mtemp $(\mathrm{r}=-0.53$, see Figure 3$)$. Such species seemed to have a phenological pattern of sporocarp production associated with the dry season (January-May). In contrast, the data suggested $H$. calyculata to be a species with high production of sporocarps during the rainy season (June-December) with the influence of ENSO. C. fruticulosa was linked to the average relative humidity and showed the highest production of sporocarps during the rainy season (Figure 4) and P. compressum showed a pattern of sporocarp production associated with the dry season and was linked to precipitation. In a similar manner, data suggested that A. cinerea and S. fusca are species with a high production of sporocarps during the rainy season.

As expected, there were not enough data to observe seasonality in most of the rare species. However, Lycogala conicum Pers., Fuligo septica (L.) F.H. Wigg., P. galbeum Wingate, recorded just once, were observed only during the dry months of the year. Similarly, Perichaena depressa Lib. was recorded only during dry months and Comatricha nigra (Pers. ex J.F. Gmel.) J. Schröt. only during the rainy season. An interesting case was observed in the pattern of records for Tubifera microsperma (Berk. \& M.A. Curtis) G.W. Martin, Metatrichia vesparia (Batsch) Nann.-Bremek. ex G.W. Martin \& Alexop., $P$. bogoriense Racib., P. melleum (Berk. \& Broome) Massee, and $P$. tenerum Rex. These species were recorded only during the "warm" ENSO periods between October 2018-June 2019 and November 2019-March 2020 , independent of the dry or rainy seasons. Interestingly, during those "warm" ENSO periods, the local climate data showed that $4 \mathrm{dPrec}$ was $80 \%$ lower $(t=3.48, P=0.001)$ and average temperature was $4 \%$ cooler $(t=3.70, P=0.001)$ than during "neutral" months. Such data suggested a potential association between the climatic characteristics of the "warm" periods and the presence of rarely observed species.

\section{Discussion}

Patterns of sporocarp production in myxomycetes are difficult to analyze. The process of sporocarp formation is an example of a complex system that does not rely on just one or even a few variables to take place (Eliasson 1981, Stephenson 1988). As it occurs with other complex systems, the examination of underlying mechanisms of operation is a challenging process of abstracting the dynamics of systems from data (San Miguel et al. 2012). Since phenology, analyzed herein using reproductive structures as proxies for recurrent biological events, is also linked to a second complex system such as climate, the topic of phenology in myxomycetes is a difficult task of evaluating linked patterns between complex systems. In the environment where this study was carried out, a third layer of complexity 
Table 1. Records of myxomycetes by species and forest unit observed in the present study. Some diversity estimates are provided at the bottom and bold values represent the highest.

Species

\begin{tabular}{|c|c|c|c|}
\hline & F1 & F2 & F3 \\
\hline Arcyria cinerea & 67 & 93 & 63 \\
\hline Arcyria denudata & 33 & 46 & 52 \\
\hline Arcyria incarnata & 1 & 3 & 1 \\
\hline Arcyria insignis & 4 & 3 & 2 \\
\hline Ceratiomyxa fruticulosa & 106 & 87 & 56 \\
\hline Clastoderma debaryanum & 1 & & 2 \\
\hline Comatricha nigra & 1 & 1 & 3 \\
\hline Comatricha tenerrima & 8 & 6 & 4 \\
\hline Craterium aureum & 1 & & \\
\hline Craterium leucocephalum & 3 & & \\
\hline Cribraria cancellata & 6 & 13 & 8 \\
\hline Cribraria intricata & 14 & 6 & 23 \\
\hline Cribraria tenella & 10 & 16 & 10 \\
\hline Cribraria vulgaris & & & 1 \\
\hline Diderma hemisphaericum & 1 & 5 & 12 \\
\hline Didymium bahiense & 18 & 9 & 26 \\
\hline Didymium clavus & 3 & 6 & 5 \\
\hline Didymium difforme & & 2 & \\
\hline Didymium dubium & & & 1 \\
\hline Didymium minus & & 3 & 4 \\
\hline Didymium squamulosum & 22 & 13 & 12 \\
\hline Fuligo septica & 1 & & \\
\hline Hemitrichia calyculata & 231 & 221 & 294 \\
\hline Hemitrichia serpula & 6 & 2 & \\
\hline Lamproderma scintillans & 2 & 8 & 5 \\
\hline Lycogala conicum & & & 2 \\
\hline Lycogala epidendrum & 31 & 43 & 25 \\
\hline Lycogala exiguum & 1 & 1 & 1 \\
\hline Metatrichia vesparia & 3 & & \\
\hline Perichaena chrysosperma & & & 3 \\
\hline Perichaena depressa & & 2 & \\
\hline
\end{tabular}

\section{Forest Unit}




\section{Species}

\begin{tabular}{|c|c|c|c|}
\hline Physarella oblonga & & 1 & \\
\hline Physarum album & 9 & 28 & 8 \\
\hline Physarum bivalve & 3 & & 3 \\
\hline Physarum bogoriense & & 1 & \\
\hline Physarum cinereum & 3 & 2 & 3 \\
\hline Physarum compressum & 42 & 24 & 74 \\
\hline Physarum didermoides & 16 & 23 & 9 \\
\hline Physarum galbeum & & 2 & 8 \\
\hline Physarum globuliferum & & & 1 \\
\hline Physarum javanicum & 1 & 7 & 7 \\
\hline Physarum melleum & 2 & 1 & \\
\hline Physarum pusillum & 6 & 4 & 2 \\
\hline Physarum stellatum & & 1 & \\
\hline Physarum tenerum & & 3 & 1 \\
\hline Physarum viride & 5 & 6 & 14 \\
\hline Stemonitis axifera & 8 & 7 & 5 \\
\hline Stemonitis fusca & 40 & 31 & 19 \\
\hline Stemonitis splendens & 1 & & \\
\hline Stemonitopsis aequalis & 10 & 6 & 2 \\
\hline Stemonitopsis hyperopta & & 3 & \\
\hline Tubifera microsperma & & 9 & 2 \\
\hline Trichia decipiens & & & 2 \\
\hline Trichia favoginea & 1 & & 1 \\
\hline Number of records & 721 & 748 & 776 \\
\hline Number of species & 38 & 40 & 41 \\
\hline Simpson’s Diversity & 0.85 & 0.86 & 0.82 \\
\hline Shannon’s Diversity & 2.52 & 2.64 & 2.48 \\
\hline Shannon’s Evenness & 0.32 & 0.35 & 0.29 \\
\hline Chao 1 Estimator & 53 & 43 & 44 \\
\hline
\end{tabular}

\section{Forest Unit}

F1

F2

F3 
can be added when niche partitioning in tropical myxomycetes is considered. The non-systematic character of most available myxomycete data, as mentioned previously, has limited the number of good examples of studies of phenological patterns in myxomycetes, as Novozhilov et al. (2017) very accurately pointed out. In this manner, the observed relationships shown herein, after a systematic effort of field surveying over 30 months of observation, are highly likely not random and thus valuable for the understanding of myxomycete ecology.

As such, the degree of association between the number of records, as a response variable, and the average monthly relative humidity, the accumulated precipitation of the previous four days, and ONI in the multiple correlation models is remarkable. Those simple models can explain a large percentage of the variability associated with the complexity of sporocarp production in the study area. Results showed that local climate is the primary driver of fruiting patterns and that regional oscillations influence general sporocarp production. Of course, as observed in the data as well, different species display different fruiting dynamics, which simply demonstrates diverse interactions with environmental variables (Eliasson 1981). However, it seems likely that the remaining ecological effect on sporocarp production in Neotropical myxomycetes resides in finer aspects such as ecosystem structure, substrate quality/availability and biotic interactions, as observed in several previous studies (Schnittler \& Stephenson 2000, Schnittler \& Stephenson 2002, Rojas et al. 2008).

Even though the present study has shown that sporocarps of myxomycetes are practically always present under Neotropical field conditions, an observation also made by other researchers (de Lima \& Cavalcanti 2015), the differences observed in the three forest units dominated by different tree species support the idea that finer aspects of the ecosystem have a differential effect on sporocarp production (Costa et al. 2014). However, it was interesting to observe that despite taxonomic differences in tree composition and myxomycete assemblages among forest units, patterns such as higher productivity of sporocarps with more even distribution of species were observed across all units during the months of the year with more rain. Such an observation has already been made in other studies in tropical areas (Ogata et al. 1996, Ko Ko et al. 2011) and have been suggested to be the general pattern in the tropics (Novozhilov et al. 2017). Some investigations in Costa Rica comparing wet-dry tropical forests (Rojas \& Valverde 2015) and seasonal dynamics (Rojas et al. 2016) show the opposite pattern but using data from different recording techniques. In general, myxomycetes can clearly thrive over a wide range of conditions (Estrada-Torres et al. 2009) and too much precipitation can affect the integrity of sporocarps, but the results presented herein support the idea that wet substrates during the rainy months are more favorable for most species to produce sporocarps under tropical conditions. As such, those wet-but not soaked-substrates induce a taxonomic homogenization on most species that promotes the formation of sporocarps and increases the spatial similarity of myxomycete assemblages.

In terms of phenological analysis, the seasonality of sporocarp production observed for different species during the present investigation has been suggested in other tropical studies (Costa et al. 2014). However, as explained by Tonkin et al. (2017), the temporal shaping of species dynamics (phenology) in natural systems should not be explained only in terms of seasonality but also in terms of predictability. As such, the reliability of event recurrence, analyzed herein as one central point of the phenological approach, is particularly important to be addressed as well. As mentioned earlier, most tropical studies fall short in addressing such predictability due to constraints in the temporal extent of data evaluation. In the present study, somewhat more robust for that type of analysis, such recurrence of events (or predictability) was observed in the dynamics of sporocarp production (shown as arrows in Figs. 3 and 4). This is a remarkable result for the evaluation of fruiting patterns in tropical areas, typically addressed as systems where "there are always going to be myxomycetes." Even though the latter idea is not completely wrong, species dynamics still shape the species assemblages in a temporal manner, just as in temperate forests, but presumably with a different degree of effect on myxomycetes (Rojas \& Stephenson 2020).

This recurrence of sporocarp formation has also been observed, with different levels of predictability 
associated with different species, in other long-term studies (Eliasson 1981, Stephenson 1988) and more recent data showed that extreme climate events in temperate areas can have a strong effect on sporocarp formation in nivicolous myxomycetes (Schnittler et al. 2015). In the present study, the occurrence of rare species was observed in association with the regional climate oscillations of the El Niño-Southern Oscillation events. As such, phenomena such as climate change, habitat loss, and extreme natural disasters can have an important effect on sporocarp production of myxomycetes, including tropical assemblages, with subsequent effects on their ecological dynamics. Future long-term studies on myxomycetes are necessary for other ecological patterns to be revealed, but always considering the power of comparability by using standard methodologies over time, which would make data generation more meaningful for integrative global evaluations.

\section{Acknowledgements}

This study was financed by the Vicerrectoría de Investigación of Universidad de Costa Rica through project 570-B8-006 of the Finca Experimental Interdisciplinaria de Modelos Agroecológicos (FEIMA) in Turrialba. Special gratitude is extended to the Engineering Research Institute (INII) for granting time to the first author to carry out this study and to Werner Rodriguez Montero for his administrative and logistic support. We would like to thank Shiori Nakajima and the Japanese International Cooperation Agency (JICA) for their support in the field surveys and interest in myxomycete research.

\section{References}

Abernethy, K., Bush, E.R., Forget, P.M., Mendoza, I., Morellato, L.P.C. 2018: Current issues in tropical phenology: a synthesis. Biotropica 50: 477-482.

Bortnikov, F.M., Matveev, A.V., Gmoshinskiy, V.I., Novozhilov, Y.K., Zemlyanskaya, I.V., Vlasenko, A.V., Schnittler, M., Shchepin, O.N. \& Fedorova, N.A. 2020. Myxomycetes of Russia: a history of research and a checklist of species. Karstenia 58: 316-373.

Costa, A.A.A., Bezerra, A.C.C., de Lima, V.X., Cavalcanti, L.H. 2014: Diversity of myxomycetes in an environmentally protected area of Atlantic Forest in northeastern Brazil. Acta Botanica Brasilica 28: 445-455.

Dagamac, N.H.A., Novozhilov, Y.K., Stephenson, S.L., Lado, C., Rojas, C., dela Cruz, T.E., Unterseher, M., \& Schnittler, M. 2017: Biogeographical assessment of myxomycete assemblages from Neotropical and Asian Paleotropical forests. Journal of Biogeography 44: 1524-1536.

De Lima, V.X., Cavalcanti, L.H. 2015: Ecology of lignicolous myxomycetes in Brazilian Atlantic rain forest. Mycological Progress 14: 1-9.

Eliasson, U. 1981: Patterns of occurrence of myxomycetes in a spruce forest in South Sweden. Holartic Ecology 4: 20-31.

Estrada-Torres, A., Wrigley de Basanta, D., Conde, E. \& Lado, C. 2009: Myxomycetes associated with dryland ecosystems of the Tehuacán-Cuicatlán Valley Biosphere Reserve, Mexico. Fungal Diversity 36: 17-56.

Ko Ko, T.W., Stephenson, S.L., Hyde, K. D., Lumyong, S. 2011: Influence of seasonality on the occurrence of myxomycetes. Chiang Mai Journal of Science 38: 71-84.

Lieth, H. 1974: Purposes of a Phenology Book. In: Lieth, H (Ed.). Phenology and seasonality modelling, 3-22.

Springer Science, New York.

Novozhilov, Y.K., Rollins, A.W. \& Schnittler, M. 2017: Ecology and distribution of myxomycetes. In: Stephenson, S.L. \& Rojas, C. (Eds). Myxomycetes: Biology, Systematics, Biogeography and Ecology. 253-297. Academic Press, London.

Ogata, N., Rico-Gray, V. \& Nestel, D. 1996: Abundance, richness, and diversity of myxomycetes in a Neotropical Forest Ravine. Biotropica 28: 627-635. 
Quesada-Chacón, A., Nakajima, S., Rojas, P.A. \& Rojas, C. 2020: Cuantificación estructural forestal según uso de la tierra y reservas de carbono de FEIMA, Turrialba, Costa Rica. Revista Ingeniería 30: 59-74.

Rojas, C., Schnittler, M., Biffi, D. \& Stephenson, S.L. 2008: Microhabitat and niche separation in species of Ceratiomyxa. Mycologia 100: 843-850.

Rojas, C. \& Valverde, R. 2015: Ecological patterns of lignicolous myxomycetes from two different forest types in Costa Rica. Nova Hedwigia 101: 21-34.

Rojas, C., Valverde, R., Calvo, E. 2016: Does elevation influence the distributional patterns of tropical myxomycetes? A case study in Costa Rica. Mycology 7: 45-52.

Rojas, C. \& Stephenson, S.L. 2020: Comparative analysis on datasets of myxomycetes associated with boreal, temperate, and tropical regions of North America. Karstenia 58: 190-200.

Rollins, A.W. \& Stephenson, S.L. 2013: Myxomycetes associated with grasslands of the western central United States. Fungal Diversity 59: 147-158.

San Miguel, M., Johnson, J.H., Kertesz, J., Kaski, K., Díaz-Guilera, A., MacKay, R.S., Loreto, V., Érdi, P. \& Helbing, D. 2012: Challenges in complex systems science. The European Physical Journal Special Topics 214: 245-271.

Schnittler, M., Stephenson, S.L. 2000: Myxomycete biodiversity in four different forest types in Costa Rica. Mycologia 92: 626-637.

Schnittler, M., Stephenson, S.L. 2002: Inflorescences of Neotropical herbs as a newly discovered microhabitat for myxomycetes, Mycologia 94: 6-20.

Schnittler, M., Erastova, D.A., Shchepin, O.N., Heinrich, E. \& Novozhilov, Y.K. 2015: Four years in the Caucasus - observations on the ecology of nivicolous myxomycetes.

Fungal Ecology 14: 105-115.

Schnittler, M., Dagamac, N.H.A. \& Novozhilov, Y. 2017:

Biogeographical patterns in Myxomycetes. In: Stephenson, S.L. \& Rojas, C. (Eds). Myxomycetes: Biology, Systematics, Biogeography and Ecology. 299-332. Academic Press, London.

Shchepin, O., Schnittler, M., Dagamac, N.H.A., Leontyev, D.V. \& Novozhilov, Y.K. 2019: Unexplored diversity of microscopic myxomycetes: evidence from environmental DNA.

Plant Ecology and Evolution 152: 499-506.
Stephenson, S.L. 1988: Distribution and ecology of Myxomycetes in temperate forests. I. Patterns of occurrence in the upland forests of southwestern Virginia. Canadian Journal of Botany 66: 2187-2207.

Stephenson, S.L., Rojas, C. 2020: Mosses as spore traps for myxomycetes. Sydowia 72: 215-219.

Stephenson, S.L., Schnittler, M., Lado, C., Estrada-Torres, A., Wrigley de Basanta, D., Landolt, J.C., Novozhilov, Y.K., Clark, J., Moore, D.L. \& Spiegel, F. 2004: Studies of Neotropical Mycetozoans. Systematics and Geography of Plants 74: 87-108.

Tonkin, J.D., Bogan, M.T., Bonada, N., Ríos-Touma, B. \& Lytle, D.A. 2017. Seasonality and predictability shape temporal species diversity. Ecology 98: 1201-1216. 